\title{
QUANTIFICATION OF MUNICIPAL SOLID WASTE MANAGEMENT IN THE UNITED STATES - WITH COMPARATIVE ANALYSIS TO OTHER ESTIMATES
}

\section{Bryan Staley * and Debra Kantner}

Environmental Research and Education Foundation (EREF), Raleigh NC, USA

Article Info:
Received:
20 February 2018
Revised:
23 July 2018
Accepted:
22 August 2018
Available online:
10 September 2018
Keywords:
Waste generation
Municipal solid waste
Recycling
Disposal
Waste accounting

Article Info:

20 February 2018

Accepted:

2 August 2018

10 September 2018

Keywords:

Disposal

Waste accounting

\begin{abstract}
The Environmental Research and Education Foundation (EREF) recently completed a study to quantify the amount of MSW managed in the United States. The study represents the first to use a bottom-up, facility-based methodology in the U.S. to improve accuracy and more discretely track the amount of waste managed. Over 9,000 facilities managing municipal solid waste (MSW) were identified through the course of the study (landfills, WTE incinerators, recycling facilities, composting operations, and anaerobic digesters), and information on the amount and types of waste managed were collected. Results suggest 1.4 times more MSW is managed in 2013 than previously suggested by U.S. Environmental Protection Agency (U.S. EPA) estimates. Data show that the majority of MSW was landfilled and the least amount of tonnage was composted.
\end{abstract}

\section{INTRODUCTION}

\subsection{MSW estimates in the United States}

Each year a significant amount of municipal solid waste (MSW) is generated in the United States, the collection and subsequent management of which has implications for sustainability. Worldwide the waste sector comprises approximately $18 \%$ of global anthropogenic $\mathrm{CH}_{4}$ emissions (Bogner et al., 2007). In the U.S. waste disposal accounts for $22 \%$ of national anthropogenic $\mathrm{CH}_{4}$ emissions (US EPA, 2010). Additionally, landfills are among the largest anthropogenic sources of $\mathrm{CH}_{4}$ in the U.S. and are frequent targets for mitigation (Chanton et al., 2011). As such, accurately tracking both the quantity of waste diverted from and deposited in U.S. landfills is key to understanding sustainability from both materials management and global climate change perspectives.

Although both state and federal entities seek to quantify annual waste management, estimates of nationwide MSW generation and fractionation between management endpoints (i.e. landfills, incinerators, recycling facilities, and composting operations) have historically differed greatly (Tonjes and Greene, 2012). The two primary sources for nationwide MSW generation, recovery and disposal information have been the US Environmental Protection Agency's (US EPA) annual Facts and Figures report, and the biennial State of Garbage series published by Biocycle magazine through Columbia University. In 2008, the most recent year for which both sources estimated MSW generation, estimates differed by 126.9 million metric tons, or about 50\% (Tonjes and Greene, 2012).

Differences between estimates are attributable to a number of factors, primarily differences in methodology and inability to resolve disparate MSW definitions. The US EPA implements a top-down (material flow) methodology in which production, import and export values are coupled with estimated product life to approximate annual waste generation. Management fractionation is approximated using data for remanufacturing (recycling), recovery (composting) and incineration, with the net assumed as landfilling. By contrast, Biocycle estimates are derived from a middle-up methodology in which state agency-provided statistics are aggregated to provide national-level data. As a result of dependency on state agency data reporting structures, these estimates are susceptible to error introduced by factors such as differences in state permitting and reporting requirements, data collection and calculation methodologies, and material types included in state definitions of MSW.

One approach to increase accuracy of waste management estimates is the use of a bottom-up facility-based methodology where tonnage and material data is aggregated across all MSW management facilities (i.e. landfills, incinerators, recycling facilities and composting opera- 
tions). By aggregating facility data, rather than state-reported statistics, tonnage data is captured from those entities not required to report to the respective states. The inclusion of material data (e.g. fraction MSW, industrial waste, construction and demolition waste) allows for the use of a consistent definition of MSW for all states. EREF has used this bottom-up facility-based methodology to estimate MSW management in 2010 and 2013 for each state and the United States as a whole (EREF, 2016).

\subsection{Nomenclature}

EREF: Environmental Research \& Education Foundation IPCC: Intergovernmental Panel on Climate Change MRF: Material Recovery Facility; typically, a highly-automated facility for the processing, sortation, and baling of recyclable commodity materials

MSW: Municipal Solid Waste, i.e. waste generated in residential, commercial and institutional sectors

Non-MRF: Recycling facility not fitting the description of a Material Recovery Facility (MRF); facility for the aggregation and/or densification of recyclable commodity materials.

OECD: Organization for Economic Co-operation and Development

US EPA: United States Environmental Protection Agency WTE: Waste-to-Energy incineration with energy recovery

\section{QUANTIFYING MSW MANAGEMENT}

\subsection{Approach}

The use of a bottom-up methodology necessitates identification of all waste management infrastructure, as no standardized count or database exists for facilities due to inconsistent notification and permitting requirements between states. Facilities were identified and reported tonnage was aggregated to estimate the amount of MSW managed at the country's landfills, waste-to-energy incinerators, composting operations, and recycling facilities.

Over 9,000 facilities managing MSW materials were identified as operational during 2013, the majority of which were associated with material recovery (i.e. recycling and composting) (Table 1). Two distinct types of recycling facilities were identified: traditional material recovery facilities (MRFs) with highly automated sorting and baling lines; and smaller material aggregators (termed "non-MRFs" in the study) which typically perform minimal sorting, may accept only limited material types (e.g. steel and aluminum cans exclusively), and little automation of the processing line.

\subsection{MSW management in the U.S.}

Results indicate approximately 315 million metric tons of MSW was collected in 2013, and subsequently managed at MSW facilities (Table 2). The majority (64\%) was disposed of in landfills. Approximately $21 \%$ of generated MSW was recovered at recycling facilities (both highly-automated MRFs and non-MRFs). It is important to note this figure includes only commodity recyclables that are part of the US EPA definition of MSW (i.e. paper, glass, plastic, and non-scrap metals from residential, commercial, and institutional sources). An additional $6 \%$ of MSW was recovered for composting, resulting in a $27 \%$ combined rate for recycling and composting. The remaining MSW was managed at waste-to-energy facilities.

\subsection{Comparison to other studies}

The bottom-up tonnage estimates indicate significantly more MSW is generated, recovered, and disposed in the U.S. than previously thought, based on comparison to US EPA estimates for the same year (US EPA, 2014). Total MSW generation for 2013 was estimated by US EPA as 230.5 million metric tons of MSW, a difference of 84.3 million tons or approximately $37 \%$ (Table 3 ).

The largest difference between estimates exists for landfilled tonnage. This is attributable, in part, to the differences in methodology between the two estimates. Although tonnage and material data for landfills is widely available through reporting data and scale ticket measurements, the material-flow methodology from which US EPA derives its estimates does not utilize this data. Instead, landfilled tonnage is estimated as the net of estimated generation minus estimated remanufacturing, recovery, and incineration (US EPA, 2014). By contrast the EREF's facility-based methodology uses scale reports for Subtitle D landfills, providing increased granularity and accuracy. Given that Subtitle D landfills can also manage a variety of non-MSW non-hazardous wastes (i.e. construction and demolition debris (C\&D), non-hazardous sludge, and industrial solid waste), one key element of this assessment was to use site-specific material data to separate MSW from non-MSW tonnage. Detailed material data was available in 14 states, representing 37\% of landfilled tonnage in 2013. Data suggests one-third of material accepted at MSW landfills was non-MSW, with individual state values ranging

TABLE 1: Number of facilities identified as processing MSW during 2013

\begin{tabular}{l|c|c} 
Type of Facility & EREF & Previous Estimates \\
\hline Recycling & 3,913 & $1,652^{\mathrm{a}}$ \\
\hdashline MRFs & 799 & $590^{\mathrm{b}}$ \\
\hline Composting & 3,494 & $3,285^{\mathrm{c}}$ \\
\hline Landfills & 1,540 & $1,802^{\mathrm{a}, \mathrm{d}}$ \\
\hline Waste-to-Energy & 81 & $94^{\mathrm{a}, \mathrm{e}}$ \\
\hline TOTAL & 9,028 & 6,833 \\
\hline
\end{tabular}

a Waste Business Journal (2014)

${ }^{\mathrm{b}}$ Berenyi (2007)

c ILSR (2014)

dIncludes some C\&D landfills

e Includes some non-MSW incinerators, such as medical waste

TABLE 2: Amount of MSW managed at identified facilities in 2013.

\begin{tabular}{l|c|c}
\hline Type of Facility & $\begin{array}{c}\text { MSW Managed } \\
\text { (million metric tons) }\end{array}$ & $\begin{array}{c}\text { Percent } \\
\text { of total }\end{array}$ \\
\hline Landfills & 201 & $64 \%$ \\
\hline Recycling & 66.2 & $21 \%$ \\
\hline Waste-to-Energy incineration & 27.9 & $9 \%$ \\
\hline Composting & 19.3 & $6 \%$ \\
\hline TOTAL & 314.8 & $100 \%$ \\
\hline
\end{tabular}


TABLE 3: Differences between EREF and US EPA estimates for 2013.

\begin{tabular}{|c|c|c|c|}
\hline Type of Facility & $\begin{array}{c}\text { EREF Estimate } \\
\text { (million metric tons) }\end{array}$ & $\begin{array}{l}\text { US EPA Estimate } \\
\text { (million metric tons) }\end{array}$ & Percent Difference \\
\hline Landfills & 201 & 121.8 & $65 \%$ \\
\hline Recycling & 66.2 & 58.7 & $13 \%$ \\
\hline Waste-to-Energy & 27.9 & 29.7 & $-6 \%$ \\
\hline Composting & 19.3 & 20.3 & $-5 \%$ \\
\hline TOTAL & 314.8 & 230.5 & $37 \%$ \\
\hline
\end{tabular}

from 9-82\% non-MSW (EREF, 2016b).

Acceptance of non-MSW materials occurred at all facility types, but was most common in landfills, composting operations, and non-MRF facilities (e.g. scrap metal processors accepting steel and aluminum cans from residential generators). As illustrated with Subtitle D landfills, facility-specific tonnage and material data was key to minimizing the inclusion of non-MSW materials in the EREF estimates and therefore minimizing sources of error existent in other studies (e.g. Biocycle). Results also suggest US EPA underestimates MSW managed via recycling, however to a lesser extent (Table 3). By contrast, US EPA may overestimate both MSW incineration and composting. This is likely due, in part, to the potential inclusion of non-MSW materials (e.g. industrial waste or agricultural biomass) in industry-reported statistics incorporated into the US EPA recovery figures.

A recent study corroborates the assertion that US EPA underestimates MSW landfilling, using facility data from the subset of Subtitle D landfills included in the GHG reporting database. Powell et. al. (2015) estimates 262 million metric tons was managed via landfill in 2012, whereas US EPA estimates 122 million metric tons for the same year: a difference of $115 \%$. With independent lines of research suggesting US EPA underestimates MSW sent to landfill, it stands to reason that a bottom-up methodology currently produces the most accurate estimate of MSW-only material deposited in landfills in the U.S.

\subsection{Comparison to international statistics}

Recently the World Bank (2012) estimated that developed countries (denoted as OECD) generated the most MSW in the world, at about $2.2 \mathrm{~kg} /$ person-day. Using the EPA values, the U.S. would actually be lower than the OECD average at $2 \mathrm{~kg} /$ person-day. However, EREF values put U.S. per capita MSW generation at $2.7 \mathrm{~kg} /$ person-day, which would make the U.S. the largest global waste generator on a per capita basis, about $23 \%$ above the OECD value and nearly $2 \frac{1}{2}$ times higher than Europe (Figure 1).

In addition to MSW generation, the management of MSW also differs by country. Statistics compiled by the World Bank (2012) indicate the percentage of MSW managed via landfilling, WTE incineration, recycling, and composting by nation. Excerpted results for 8 countries, and results from EREF's bottom-up estimates for the U.S., are shown in Figure 2. MSW management in the U.S. is most similar to that of the U.K. which exhibits an identical landfilling rate $(64 \%)$ and similar material recovery (i.e. recycling and composting) rate (26\% compared to $27 \%$ in the U.S.). Austria reported the highest material recovery rate (71.26\%). Switzerland reported the lowest landfilling rate (1\%). The highest waste-to-energy incineration rate was reported in Japan (74\%).

Differences in MSW management statistics between the U.S. and other countries indicate potential improvement through both a reduction in waste generation and an increase in material recovery (i.e. recycling and composting). The challenge to achieve these aims in the U.S. is

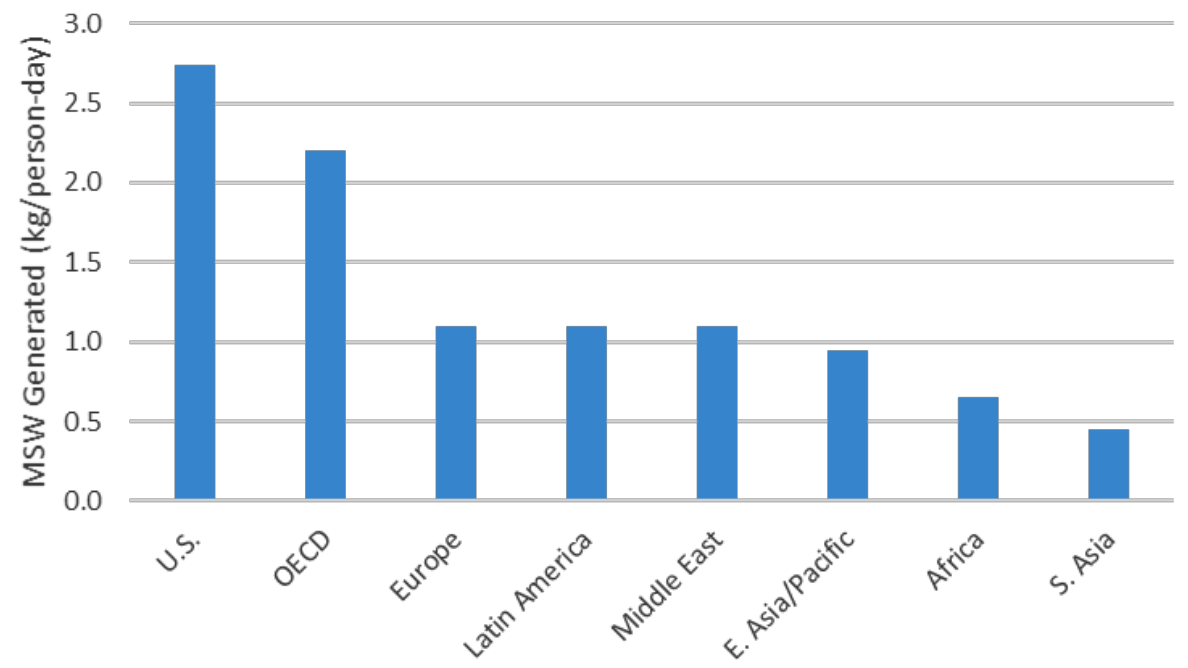

FIGURE 1: Per capita waste generation of the U.S., Europe and global regions (Note: OECD = Organization for Economic Cooperation \& Development; i.e. developed countries). 


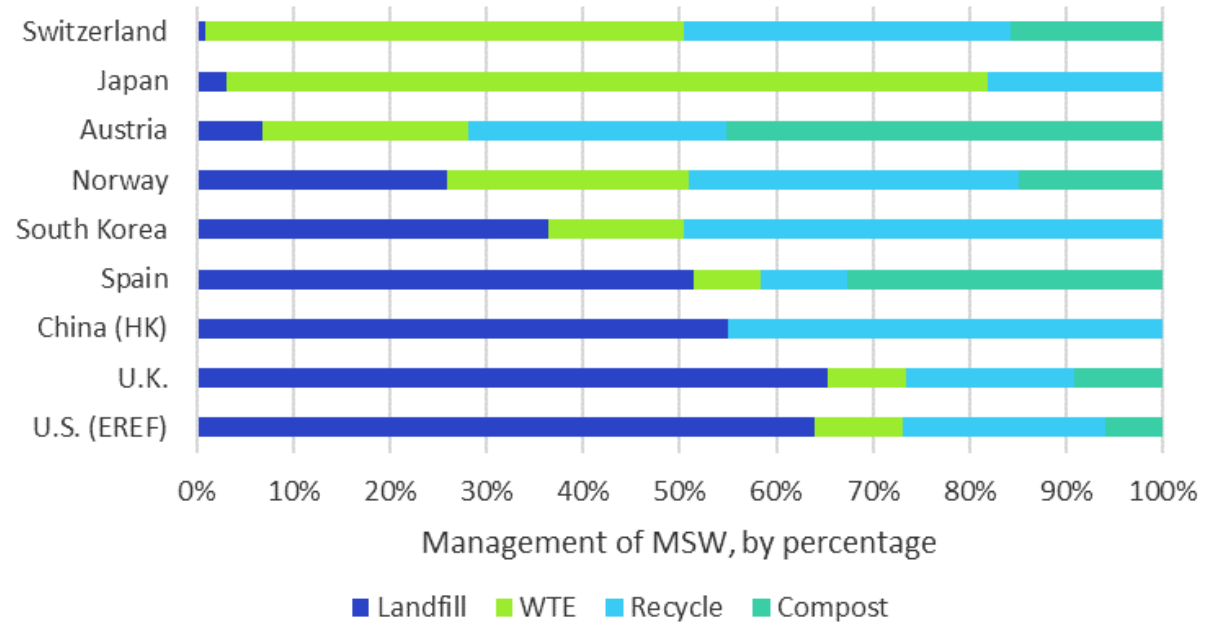

FIGURE 2: EREF estimates of U.S. MSW management compared to MSW management of selected nations (Source: World Bank, 2012).

multi-faceted, including: infrastructure, policy, and behavioral challenges. It should be emphasized that while substantial infrastructure already exists in many regions of the U.S. to divert materials from landfills, others may lack sufficient infrastructure to further increase recycling or composting rates (EREF, 2016). Policy differs across the U.S., presenting another challenge to increased recovery. For example, $53 \%$ of U.S. states ban yard waste materials from landfill while $10 \%$ mandate food waste recovery (EREF, 2015). Even in areas with sufficient infrastructure and policy drivers for recovery, challenges such as increasing recycling contamination rate exist due to participant behavior (EREF, 2016).

\section{CONCLUSIONS}

The use of a facility-based, bottom-up methodology is key to increasing accuracy of MSW management estimates (Powell et. al., 2015). The use of such methodology to estimate MSW managed in the U.S. suggests that 315 million metric tons of MSW were managed in 2013, or approximately $2.7 \mathrm{~kg} /$ capita-day. Of this, the majority of waste was landfilled, with $27 \%$ recovered via recycling and composting combined.

Results represent a 37\% difference in total MSW managed compared to US EPA estimates for the same year, with the largest difference for landfilled tonnage (65\% difference; Table 3). A large difference for landfilled MSW compared to US EPA has also been documented in other facility-based estimates (Powell et al, 2015). Landfills have consistently been listed as one of the largest sources of anthropogenic methane in the United States by entities such as the Intergovernmental Panel on Climate Change (IPCC) and the US EPA (US EPA, 2010). As such, accurate estimates of MSW generation and management are key to understanding the environmental impact of end-of-life material management decisions and assess the nationwide progress toward material recovery and sustainable materials management goals. Studies suggest that current inputs from US EPA material flow models may not provide accurate data for these efforts, however, with facility-based results suggesting that managed tonnage is greater than US EPA estimates (Table 3 ).

\section{REFERENCES}

Berenyi, E. (2007). Materials Recycling and Processing in the United States: 2007-2008 Yearbook and Directory. Westport, CT: Government Advisory Associates, Inc.

Bogner, J.; Diaz, C.; Abderlrafie Ahmed, M.; Gao, Q.; Faaij, A.; Mareckova, K.; Hashimoto, S.; Zhang, T.; Pipatti, R.. (2007). Chapter Waste Management, in: Climate Change 2007: Mitigation Contribution of Working Group III to the Fourth Assessment Report of the Intergovernmental Panel on Climate Change (IPCC). Cambridge University Press.

Chanton, J.; Abichou, T.; Langford, C.; Spokas, K.; Hater, G; Green, R; Goldsmith, D; Barlaz M. (2011). Observations on the methane oxidation capacity of landfill soils. Waste Managment, 31, 914-925.

EREF. (2016). Municipal Solid Waste Management in the U.S.: 2010 \& 2013. www.erefdn.org

EREF. (2016b). Estimating Degradable Organic Carbon in MSW Landfills and the Impact of non-MSW Materials. www.erefdn.org.

EREF. (2015). Anaerobic Digestion of Municipal Solid Waste: Report on the State of Practice. www.erefdn.org.

ILSR. (2014). State of Composting in the U.S.: What, Why, Where, \& How, Washington, D.C.: Institute for Local Self-Reliance.

Powell, J.T.; Townsend, T.G.; Zimmerman, J.B. (2015). Estimates of solid waste disposal rates and reduction targets for landfill gas emissions. Nat. Clim. Change, 6, 162-165.

Staley, B. and Kantner, D. (2015). State of Organics Management [Webinar]. Waste360 University.

Tonjes, D.J.; Green, K.L. (2012). A review of national municipal solid waste generation assessments in the USA Waste Manag. Res. 30(8), 758-771.

US EPA. (2010). US Emissions Inventory 2010. Inventory of US Greenhouse gas emissions and sinks: 1990-2008. USEPA \#430-R-10006.

US EPA. (2014). Advancing Sustainable Materials Management: Facts and Figures 2013. http:www.epa.gov/osw/nonhaz/municipal/ pubs/2013-advncng-ssm-rpt.pdf (Accessed June 2015).

Waste Business Journal. (2014). Directory of Waste Processing \& Disposal Sites [Data file].

World Bank. (2012). What a waste: a global review of solid waste management. March 2012, Number 15. www.worldbank.org (Accessed November 2015). 